\title{
Clinical summaries for hospitalised patients: time for higher standards
}

\section{Sunil Kripalani ${ }^{1,2,3}$}

'Section of Hospital Medicine, Division of General Internal Medicine and Public Health, Department of Medicine, Vanderbilt University Medical Center, Nashville, Tennessee, USA

${ }^{2}$ Center for Clinical Quality and Implementation Research, Vanderbilt University Medical Center, Nashville, Tennessee, USA

${ }^{3}$ Center for Effective Health Communication, Vanderbilt University Medical Center Nashville, Tennessee, USA

\section{Correspondence to} Dr Sunil Kripalani, Center for Clinical Quality and Implementation Research Vanderbilt University Medical Center, 2525 West End Ave, Suite 1200, Nashville, TN 37203,USA; sunil.kripalani@ vanderbilt.edu

Commentary on 'Opportunities to Improve Clinical Summaries for Patients at Hospital Discharge'

Accepted 30 June 2016 Published Online First 19 July 2016

\section{SLinked}

http://dx.doi.org/10.1136/ bmjqs-2015-005201

\section{CrossMark}

To cite: Kripalani $S$.

BMJ Qual Saf

2017;26:354-356.
The average person remembers less than half of the information provided by healthcare professionals during a medical visit. ${ }^{1}$ The situation is arguably most challenging for patients leaving the hospital, where acute illness, sleep deprivation and delirium add to the challenge of learning and memory. ${ }^{2} 3$ Indeed, research has shown that after hospital discharge, only $59.6 \%$ of patients are able to accurately describe their discharge diagnoses, and $43.9 \%$ can accurately recall follow-up appointments. ${ }^{4}$ Approximately one-third of patients have difficulty understanding their discharge medication regimen. ${ }^{5}$

It is not the patients' fault. Hospital resources and processes of care are oriented toward acute treatment. They are not as well designed to provide highquality patient education in the hospital and across the transition home. Few hospitals have fully developed their capacity as 'health-literate healthcare organisations', which involves providing patients with information that is easy to understand and helping them navigate their care, particularly in high-risk situations like hospital discharge. ${ }^{67}$

In this context, giving patients a clinical summary to take home has the potential to serve as a valuable resource for patients and their caregivers. In theory, this document should clearly describe the patient's medical conditions, medications, other self-care instructions and next steps for follow-up and recovery. Yet, as shown in this issue of the journal, ${ }^{8}$ clinical summaries generated by electronic health records (EHRs) fall far short of this goal.

Sarzynski and colleagues performed a descriptive study in two US hospitals, examining 100 clinical summaries generated through commercially available EHRs. ${ }^{8}$ In terms of content, they found that clinical summaries generally included administrative information about the hospitalisation, such as the name of the patient and diagnoses; these are the items most easily extracted from the EHR. However, summaries failed to reliably include content most relevant for the patient's ongoing self-management, such as discharge instructions, follow-up appointments, what problems to watch for and a call-back number; all documents were missing one or more of these items.

The authors also examined the document organisation, readability and format. An interesting and innovative aspect of this article is the use of the Patient Education Materials Assessment Tool (PEMAT) to guide this critique. The PEMAT was developed in 2013 to rate print or audiovisual materials on how understandable and actionable they are. ${ }^{9}$ It is a good tool, which builds on the Suitability Assessment of Materials (SAM), ${ }^{10}$ which patient educators have used for many years to evaluate documents. Both the PEMAT and SAM go beyond a simple test of reading grade level to provide a robust, structured approach to assess document quality along multiple domains. They can also serve as a checklist to guide the creation or revision of patient education materials. For example, the PEMAT domains remind us that it is important to use everyday language, define medical terms, present information in a logical sequence and use visual aids that reinforce rather than distract from content. $^{9}$

High-quality patient education materials will earn PEMAT or SAM scores in the range of $70 \%-100 \% .{ }^{11} 12$ The scores for clinical summaries in this study, on the other hand, ranged from $14.6 \%$ to $41.2 \%$, depending on the rater, hospital and domain. ${ }^{8}$ This performance is quite disappointing. Of the 26 PEMAT dimensions, clinical summaries rated well on only 4-use of active voice, not expecting the reader to perform calculations, clearly identifying at least one action the reader can take and addressing the reader directly (note: this is pretty much the 
same as using active voice). It would actually be quite difficult to find patient education materials in other contexts which score so poorly.

We need to do better. As it relates to patient education materials, the science of effective health communication is well known. A number of excellent resources clearly describe how to create high-quality, patient-centred materials. ${ }^{10}$ 13-16 They have been used for years in the development of patient education brochures, newsletters and websites. They have even served as a basis for patient-centred discharge instructions in some transitional care interventions. ${ }^{17-19}$ Why, then, do the patient-facing materials generated by EHRs not follow these best practices?

According to a National Academy of Medicine workshop on improving patient understanding of discharge instructions, ${ }^{20}$ there are many reasons. First, hospitals have a high degree of reliance on EHR vendors to determine content and format of documents, and modifications require additional programming. Second, from a technical standpoint, it is more difficult to produce 2 pages of well-formatted text than 10 pages of unformatted text. Third, the automation process involved in generating clinical summaries imports information that may be incomplete, duplicative or contain errors, and was not originally intended for this document. Fourth, a desire to include content recommended by practice guidelines, clinical pathways or quality metrics (eg, advice to quit smoking) results in long documents that may obscure the information most relevant to patients in the immediate postdischarge period.

A recent multicentre study of nearly 1000 readmitted patients implicated patient understanding and the ability to self-manage as the most common contributors to hospital readmission. ${ }^{21}$ The number one preventive strategy endorsed by physicians in this study was to provide patients with better discharge instructions and support.

In the quest to reduce hospital readmission, it is time to turn more attention to preventable causes, ${ }^{22}$ including the poor quality of educational documents and summaries that patients receive when they leave the hospital. Simply providing patients with better clinical summaries is unlikely to produce large gains on its own. ${ }^{23}$ However, as part of multicomponent transitions of care intervention, providing patient education to promote self-management was associated with significantly greater odds of success in reducing readmission. ${ }^{24}$

Hospitals and EHR vendors should work together to improve clinical summary content, organisation and format, using the PEMAT framework as a guide ${ }^{9}$ and looking to models that have been developed previously. ${ }^{20}$ A concerted effort may yield improvements in readmission rates and in other areas such as patient understanding, medication errors, adverse events, emergency department visits and patient experience ratings. Clearly, there is much work to be done in both implementation and evaluation. By shining light on the extent of the problem, Sarzynski and colleagues provide us an important early step on this journey.

Competing interests None declared.

Provenance and peer review Commissioned; internally peer reviewed.

\section{REFERENCES}

1 Kessels RP. Patients' memory for medical information. J R Soc Med 2003;96:219-22.

2 Coleman EA, Chugh A, Williams MV, et al. Understanding and execution of discharge instructions. Am J Med Qual 2013;28:383-91.

3 Lindquist LA, Go L, Fleisher J, et al. Improvements in cognition following hospital discharge of community dwelling seniors. J Gen Intern Med 2011;26:765-70.

4 Horwitz LI, Moriarty JP, Chen C, et al. Quality of discharge practices and patient understanding at an academic medical center. JAMA Intern Med 2013;173:1715-22.

5 Kripalani S, Henderson LE, Jacobson TA, et al. Medication use among inner-city patients after hospital discharge: patient reported barriers and solutions. Mayo Clin Proc 2008;83:529-35.

6 Brach C, Keller D, Hernandez LM, et al. Ten attributes of health literate health care organizations. IOM roundtable on health literacy. Washington, DC: National Academy of Medicine, 2012. https://nam.edu/perspectives-2012-tenattributes-of-health-literate-health-care-organizations/

7 Kripalani S, Wallston KA, Cavanaugh KL, et al. Measures to assess a health literate organization. Commissioned report. Washington DC: National Academy of Medicine, 2014. http:// www.nationalacademies.org/hmd/ /media/Files/Activity $\%$ 20Files/PublicHealth/HealthLiteracy/Commissioned-Papers/ Measures_Assess_HLO.pdf

8 Sarzynski E, Hashmi H, Subramanian J, et al. Opportunities to improve clinical summaries for patients at hospital discharge. BMJ Qual Saf 2016; doi:10.1136/bmjqs-2015-005201

9 Shoemaker SJ, Wolf MS, Brach C. The patient education materials assessment tool (PEMAT) and user's guide. Rockville, MD: Agency for Healthcare Research and Quality, 2016.

10 Doak CC, Doak LG, Root JH. Teaching patients with low literacy skills. 2nd edn. Philadelphia: JB Lippincott Co., 1998.

11 Shoemaker SJ, Wolf MS, Brach C. Development of the Patient Education Materials Assessment Tool (PEMAT): a new measure of understandability and actionability for print and audiovisual patient information. Patient Educ Couns 2014;96:395-403.

12 Wolff K, Chambers L, Bumol S, et al. The PRIDE (Partnership to Improve Diabetes Education) Toolkit: development and evaluation of novel literacy and culturally sensitive diabetes education materials. Diabetes Educ 2016;42:23-33.

13 Centers for Disease Control and Prevention. Gateway to Health Communication \& Social Marketing Practice. http://www.cdc. gov/healthcommunication/ (accessed 24 Jun 2016).

14 U.S. Department of Health and Human Services National Cancer Institute. Making Health Communication Programs Work. http://www.cancer.gov/publications/ health-communication/pink-book.pdf (accessed 24 Jun 2016).

15 Centers for Medicare and Medicaid Services. Toolkit for Making Written Material Clear and Effective. https://www.cms. gov/Outreach-and-Education/Outreach/WrittenMaterialsToolkit/ index.html? redirect $=/$ WrittenMaterialsToolkit (accessed 24 Jun 2016).

16 U.S. Department of Health and Human Services. https://www. usability.gov/ (accessed 24 Jun 2016). 


\section{Editorial}

17 Jack BW, Chetty VK, Anthony D, et al. A reengineered hospital discharge program to decrease rehospitalization: a randomized trial. Ann Intern Med 2009;150:178-87.

18 Hansen LO, Greenwald JL, Budnitz T, et al. Project BOOST: effectiveness of a multihospital effort to reduce rehospitalization. J Hosp Med 2013;8:421-7.

19 Kripalani S, Roumie CL, Dalal AK, et al. Effect of a pharmacist intervention on clinically important medication errors after hospital discharge: a randomized controlled trial. Ann Intern Med 2012;157:1-10.

20 Institute of Medicine. Facilitating patient understanding of discharge instructions: Workshop summary. Washington DC: The National Academies Press, 2014.
21 Herzig SJ, Schnipper JL, Doctoroff L, et al. Physician perspectives on factors contributing to readmissions and potential prevention strategies: a multicenter survey. J Gen Intern Med 2016; doi:10.1007/s11606-016-3764-5

22 Lavenberg JG, Leas B, Umscheid CA, et al. Assessing preventability in the quest to reduce hospital readmissions. J Hosp Med 2014;9:598-603.

23 Hansen LO, Young RS, Hinami K, et al. Interventions to reduce 30-day rehospitalization: a systematic review. Ann Intern Med 2011;155:520-8.

24 Burke RE, Guo R, Prochazka AV, et al. Identifying keys to success in reducing readmissions using the ideal transitions in care framework. BMC Health Serv Res 2014;14:423. 